\title{
A Vivência Materna da Função de Cuidar no Período de Dependência da Criança*
}

\author{
Amanda Schöffel Sehn** (1) \& Rita de Cássia Sobreira Lopes (10 \\ Universidade Federal do Rio Grande do Sul, Porto Alegre, RS, Brasil
}

\begin{abstract}
RESUMO - Buscou-se investigar a vivência materna da função de cuidar no período de dependência da criança. Participaram desse estudo de caso múltiplo três duplas mãe-criança. Foram realizadas entrevistas semiestruturadas em seis momentos do desenvolvimento infantil $\left(6^{\circ}, 12^{\circ}, 18^{\circ}, 24^{\circ}, 36^{\circ}, 48^{\circ}\right.$ mês $)$, cujos dados foram analisados por meio do relato clínico. Evidenciou-se que a função de cuidar exige grande disponibilidade materna, especialmente quanto aos movimentos de dependência e independência da criança. Apesar da satisfação ao cuidar, as mães se depararam com dificuldades e cansaço. Ainda, encontraram a possibilidade de autocuidado e de reeditar os cuidados recebidos na infância ao cuidarem do bebê. Assim, destaca-se a importância de encorajar o saber materno e legitimar a vivência de sentimentos ambivalentes no cuidado com crianças.
\end{abstract}

PALAVRAS-CHAVE: função materna, cuidar, relação mãe-bebê, desenvolvimento emocional

\section{The Maternal Experience of the Caring Function During the Child Dependency Period}

\begin{abstract}
The present study investigated the maternal experience of the caring function during child dependence period. Three mother-child pairs participated in this multiple case study. Semi-structured interviews were conducted in six distinct moments of child development (6th, 12th, 18th, 24th, 36th, 48th month). Data were analyzed by clinical report. It was evidenced that the caring function requires great maternal availability, especially regarding the child's dependence and independence movements. Despite the satisfaction in caring, mothers faced difficulties and tiredness. Still, they found the possibility of self-care and to reedit the care received in childhood when taking care of the baby. Thus, it is important to encourage maternal knowledge and legitimizing the experience of ambivalent feelings in caring for children.
\end{abstract}

KEYWORDS: maternal role, care, mother-child relation, emotional development

\footnotetext{
* O presente artigo é baseado em parte da dissertação de mestrado da primeira autora, intitulada A vivência da função materna no periodo de dependência: do sexto mês ao quarto ano de vida da criança, realizada sob orientação da segunda autora e apresentada no Programa de Pós-graduação em Psicologia da UFRGS.

**E-mail: amanda_sehn@hotmail.com

- Submetido: 28/12/2016; Revisado: 05/09/2017; Aceito: 01/02/2018
} 
No início da vida, a tarefa de cuidar ${ }^{1}$ assume fundamental importância (Barbosa, Machado, Vilela e Souza, \& ScorsoliniComin, 2010; Caron \& Lopes, 2014; Henriques, Falbo, Sampaio, Fonte \& Krause, 2015), sendo determinante para que as experiências do bebê se tornem pessoais e integradas, bem como para favorecer a constituição do indivíduo (Winnicott, 1965/2011; Winnicott, 1987/2006). Considerando a perspectiva winnicottiana, o amadurecimento infantil é marcado pela dependência absoluta e, posteriormente, relativa, que avança de forma gradual em direção a uma maior independência (Winnicott, 1987/2006).

O estágio da dependência absoluta compreende os primeiros meses de vida do bebê. Nesse período, que ocorre desde o final da gravidez até alguns meses após o nascimento, a mãe entra em um estado psicológico muito especial, denominado preocupação materna primária (Winnicott, 1958/2000). Esse estado materno é passageiro e, caso a mãe não estivesse grávida, poderia se constituir em uma doença (Winnicott, 1987/2006). A vivência de tal período também é denominada como "loucura normal", em que a mãe se encontra imersa na relação com o bebê (Winnicott, 1958/2000).

De acordo com Winnicott (1965/2011), é esperado que, na dependência absoluta, a mãe se dedique inteiramente ao bebê. No entanto, é importante que, ao longo do desenvolvimento, ela consiga sair da dependência e permita que a criança caminhe em direção a uma maior independência. Esse movimento de "saída" ocorre a partir das falhas naturais no cuidado durante a dependência relativa, em que a mãe provê uma desadaptação gradativa ao bebê (Winnicott, 1965/1983). Nesse sentido, tem-se que a indiscriminação mãe-bebê é esperada em um primeiro momento (Lopes, Prochnow, \& Piccinini, 2010), sendo marcada por um estado regressivo, em que a mãe pode se sentir tão desamparada quanto o bebê (Bick, 1986).

Durante esses estágios iniciais de dependência, destacase a função materna de holding, que consiste no primeiro ambiente do bebê e está atrelada à capacidade materna de identificação com o lactente, para proporcionar os cuidados básicos inerentes ao início da vida (Winnicott, 1965/2011). Além disso, essa função é fundamental para que o recémnascido possa avançar em direção à integração, ao mesmo tempo em que mantém sua experiência de continuidade preservada (Winnicott, 1965/1983).

Em seguida ao estágio de dependência relativa, tem-se o início da caminhada rumo à independência, caracterizada pelo processo contínuo de desenvolvimento do indivíduo, visto que raramente a maturidade completa é atingida, mesmo na idade adulta (Dias, 2003; Winnicott, 1965/1983). Quando os estágios anteriores ocorrem de forma saudável, durante a independência, a criança é capaz de, paulatinamente,

1 Entende-se que a tarefa de cuidar, assim como a função materna de cuidar, pode ser exercida por um adulto responsável pela criança - não necessariamente a mãe biológica - que se encarregue desse papel, visto que a função materna não pode ser anônima. deparar-se com o mundo e com a sua complexidade, bem como viver uma existência pessoal, considerada satisfatória (Winnicott, 1965/1983; Winnicott, 1965/2011).

Durante esses estágios é importante que a mãe exerça a função materna de cuidar, que se refere à adaptação sensível às demandas do bebê no início da vida. Dito de outro modo, diz respeito "à delicada adaptação das mães às necessidades sempre mutáveis de seus bebês" (Winnicott, 1965/2011, p. 130). Para que isso ocorra, é necessário que a mãe esteja disponível e aceite ser usada pelo bebê como objeto subjetivo, isto é, que ela permita que o bebê seja ela. Ao propiciar a identificação primária, a mãe possibilita ao bebê a experiência de ser (Winnicott, 1970/1989), a qual é a base para a experiência da continuidade de ser e das identificações que ocorrerão posteriormente à identificação primária (Dias, 2003; Winnicott, 1970/1989). Nesse sentido, o bebê não necessita de perfeição, mas de uma adaptação suficientemente boa (Winnnicott, 1951/1993). Referindo-se de outra forma, compreende-se que o bebê precisa de uma mãe que se identifique a ele temporariamente para se adaptar de forma ativa às suas necessidades. Em seguida, conforme avança o processo do desenvolvimento, tal adaptação vai diminuindo à medida em que o bebê passa a tolerar as frustações e as falhas do ambiente (Winnnicott, 1951/1993).

Ser mãe é uma tarefa bastante exigente (Caron \& Lopes, 2014), a qual é permeada por angústias catastróficas, ao mesmo tempo em que está sujeita às ansiedades do bebê (Bick, 1986). Além da perda do controle do tempo e das suas atividades (Laney, Hall, Anderson, \& Willingham, 2015), a mãe se vê diante de exigências que a sobrecarregam, não conseguindo organizar sua rotina de acordo com seu desejo (Bick, 1986). De modo semelhante, Stern (1997), ao postular sobre a constelação da maternidade, destaca a importância da reorganização da identidade materna após o nascimento do bebê. Essa tarefa está atrelada à capacidade da mãe de transformar a autoidentidade e envolve a adaptação do lugar de filha para mãe, e de esposa para genitora. Nesse sentido, Laney et al. (2015) entrevistou 30 mães com o objetivo de investigar a experiência materna acerca da mudança de identidade no processo de se tornar mãe. Dentre os resultados, destaca-se o movimento de "fazer espaço" para o bebê somado à perda da identidade da mulher logo após o nascimento do mesmo e, em seguida, à reorganização da identidade.

Considerando esses aspectos, estudos empíricos também ressaltam sentimentos ambivalentes das mães associados à gestação e ao exercício da função materna no pós-parto imediato (Barbosa et al., 2010; Strapasson \& Nedel, 2010; Zanatta \& Pereira, 2015), bem como ao longo do desenvolvimento, mais especificamente, durante o primeiro ano de vida do bebê (Murray, 2015). Nesse período é comum a mulher se deparar com as contradições da função materna, o que inclui o desejo pela retomada de atividade remunerada e o cansaço em relação à rotina doméstica (Murray, 2015). Soma-se a isto, a interação social reduzida e sentimentos como irritabilidade, dificuldades e estresse (Travassos-Rodriguez \& Féres-Carneiro, 2013; Zanatta \& Pereira, 2015). 
No entanto, ainda se tem uma visão idealizada da maternidade, a qual não considera os sentimentos hostis que a mãe pode experimentar na relação com o bebê (Azevedo $\&$ Arrais, 2005). Muitas vezes, há a idealização da própria mãe em relação à maternidade, o que dificulta o encontro com a experiência real (Laney et al., 2015). Também há o entendimento, na sociedade contemporânea, de que ao reconhecer essas dificuldades, têm-se uma mãe pouco dedicada que não têm condições suficientes para exercer um cuidado satisfatório (Travassos-Rodriguez \& FéresCarneiro, 2013). Contudo, esses aspectos se contrapõem à vivência real da função materna, que é perpassada por sentimentos tanto positivos quanto negativos (Murray, 2015; Zanatta \& Pereira, 2015).

De modo geral, a literatura tem dado pouca ênfase à vivência materna da função de cuidar, e maior destaque para outros temas, como a percepção da mãe sobre a expressão das emoções das crianças (Krippl, Ast-Scheitenberger, Bovenschen, \& Spangler, 2010); o uso de emoção no discurso materno e paterno dos anos iniciais à idade préescolar (van der Pol et al., 2015); o conhecimento das mães sobre desenvolvimento infantil (Al-Maadadi \& Ikhlef, 2015); a rotina de cuidados durante a infância (Haavind, 2011) e os sentimentos maternos frente aos estágios de desenvolvimento dos filhos (Luthar \& Ciciolla, 2016).

Apesar disso, sabe-se que as relações estabelecidas entre as mães e os seus filhos nos primeiros anos de vida são fundamentais para a constituição psíquica do indivíduo, trazendo desdobramentos para o desenvolvimento infantil (Barbosa et al., 2010; Caron \& Lopes, 2014; Henriques et al., 2015; Lopes et al., 2009; Lopes et al., 2012; Zanatta \& Pereira, 2015). Em consonância com tais aspectos, no presente estudo será enfatizada a transição entre dependência absoluta e relativa, visto a exigência desse período para as mães, bem como a importância desse período inicial para o desenvolvimento emocional. Desse modo, este estudo teve como objetivo investigar a vivência materna da função de cuidar no período de dependência, que compreende o primeiro ao quarto ano de vida da criança. Em particular, visou discutir os aspectos subjetivos da função materna frente às conquistas da criança nos primeiros quatro anos.

\section{MÉTODO}

\section{Participantes}

Participaram do estudo três mães com seus bebês, um menino e duas meninas, que no início do estudo tinham entre seis e oito meses de idade. As mães eram primíparas, tinham idade entre 28 e 32 anos e estavam casadas com os pais dos bebês (vide Tabela 1).

As participantes foram selecionadas dentre os integrantes do projeto intitulado "Impacto da creche no desenvolvimento socioemocional e cognitivo infantil: estudo longitudinal do sexto mês de vida do bebê ao final dos anos pré-escolares - CRESCI" (Piccinini, Becker, Martins, Lopes, \& Sperb, 2011) ${ }^{2}$. Na seleção das participantes foram escolhidas três

2 Essa pesquisa teve como objetivo investigar o impacto da creche no desenvolvimento socioemocional e cognitivo de crianças, desde seu sexto mês de vida até o final dos anos pré-escolares. Mais especificamente, buscou comparar, ao longo desse período, o desenvolvimento de crianças que frequentaram ou não a creche, e relacioná-lo à qualidade dos ambientes institucional e familiar. O projeto iniciou em 2011 acompanhando 77 famílias, dentre estas, 29 de bebês que frequentavam a creche (Grupo Creche) e 48 de bebês que eram cuidados prioritariamente pela mãe ou por outros cuidadores, como babá e familiares (Grupo Não Creche). Além das famílias, o estudo também contou com a participação de 18 educadoras de duas creches. O projeto envolveu seis fases de coleta de dados: $6^{\circ}$, $12^{\circ}, 18^{\circ}, 24^{\circ}, 36^{\circ}$ e $48^{\circ}$ mês de vida do bebê. Ao longo desse período, o desenvolvimento das crianças foi avaliado e foram aplicadas entrevistas e questionários às mães e aos pais, visando avaliar sua percepção sobre o desenvolvimento da criança, bem como a qualidade do ambiente familiar. Cabe ressaltar que foram também realizadas filmagens da interação livre mãe-bebê e pai-bebê (no $6^{\circ}, 12^{\circ}$ e $18^{\circ}$ mês). Por sua vez, a qualidade das creches também foi avaliada, e as educadoras preencheram questionários sobre sua percepção a respeito da adaptação da criança à creche e do seu desenvolvimento (no $6^{\circ}, 12^{\circ}$ e $18^{\circ}$ mês). mães que realizaram todos os procedimentos das seis fases do Projeto CRESCI, considerando três situações distintas de cuidado, a saber, exclusivamente materno, por babá e inserção em creche. Além disso, os casos escolhidos apresentavam uma situação cotidiana de cuidado experienciada pela mãe e por seu filho.

\section{Tabela 1}

Características sociodemográficas

\begin{tabular}{ccccccc}
\hline Caso & Mãe & $\begin{array}{c}\text { Idade } \\
\text { (anos) }\end{array}$ & Escolaridade & Bebê & $\begin{array}{c}\text { Idade } \\
\text { (meses) }\end{array}$ & Cuidador \\
\hline 1 & Isadora & 28 & Ens. Sup. & Laura & 8 & Mãe \\
2 & Camila & 32 & Pós-grad. & Bruno & 6 & Mãe/Creche \\
3 & Aline & 29 & Ens. Sup. & Ana & 8 & $\begin{array}{c}\text { Mãe/Babá/ } \\
\text { Creche }\end{array}$ \\
\hline
\end{tabular}

\section{Procedimento}

Foi utilizado um delineamento de estudo de caso múltiplo (Stake, 2006), qualitativo e de caráter longitudinal. A coleta de dados ocorreu em seis momentos distintos, a saber, no $6^{\circ}$, $12^{\circ}, 18^{\circ}, 24^{\circ}, 36^{\circ}$ e $48^{\circ}$ mês de vida da criança, de acordo com as fases de coleta de dados do Projeto CRESCI. O contato com as famílias foi realizado pelos pesquisadores integrantes do projeto, via telefone ou e-mail, de acordo com a idade das crianças, quando foram agendados encontros, nos quais a participante respondeu os instrumentos previstos para cada 
momento. Destaca-se que as entrevistas foram realizadas no Instituto de Psicologia da Universidade Federal do Rio Grande do Sul (UFRGS) ou em outro local de preferência da participante, como a residência da família.

O projeto CRESCI atende aos preceitos da resolução 466/12 (Brasil, 2012) e foi aprovado pelo Comitê de Ética e Pesquisa da Universidade Federal do Rio Grande do Sul (UFRGS) (Proc. $\left.\mathrm{N}^{\circ} 2010070\right)$ e pelo Hospital de Clínicas de Porto Alegre (Proc. $N^{\circ} 100553$ ).

\section{Instrumentos}

Quanto aos instrumentos, as mães responderam à Ficha de Dados Demográficos da Família, que buscava informações sobre os dados demográficos da família, tais como idade, renda, escolaridade, profissão, estado civil, entre outros. Em seguida, responderam à Entrevista sobre a Maternidade - $6^{\circ}$ mês (NUDIF/CRESCI 2011a), que trata sobre a experiência da maternidade e é composta por seis blocos de questões que investigam sentimentos, expectativas e crenças da mãe e do pai sobre o bebê, sobre si mesma e sobre o companheiro. Após responderam à Entrevista sobre o Desenvolvimento da Criança $-6^{\circ}$ mês (NUDIF/CRESCI, 2011b), que versa sobre o desenvolvimento infantil e contém 13 blocos de questões abertas e fechadas sobre alimentação, sono, troca de fraldas, autonomia e independência, entre outros aspectos. Essas duas entrevistas foram adaptadas conforme as fases do desenvolvimento infantil e aplicadas também aos 12 , 18,36 e 48 meses da criança.

Aos 24 meses, as mães responderam à Entrevista sobre a Relação Mãe-Bebê-24 mês (NUDIF/CRESCI, 2012), que é composta por 12 blocos que abordam questões referentes à relação das mães com seus bebês, como por exemplo, quanto à afetividade materna e o controle ou proteção materna. Em cada um dos blocos, as mães são convidadas a relatar como se relacionam com os seus filhos, refletindo sobre os seus jeitos, as suas atitudes, as suas disponibilidades emocionais e de tempo, bem como convidadas a pensar se gostariam de mudar algo na relação com o seu filho.

\section{RESULTADOS}

Com vistas a investigar a vivência materna da função de cuidar no período de dependência da criança, os dados foram analisados por meio do relato clínico (Epstein, 2011; Mordcovich, 2011). De acordo com esses autores, essa análise contempla os pressupostos da teoria e da clínica psicanalítica, uma vez que não consiste em registros de conteúdos manifestos do discurso, mas se refere a uma construção do relato entre o narrador e o pesquisador, considerando os aspectos inconscientes e o não-verbal.

Assim, a análise também enfatiza detalhes que não foram mencionados verbalmente nas entrevistas, mas puderam ser percebidos pela pesquisadora no contato com as participantes e no áudio das entrevistas ${ }^{3}$. $\mathrm{Na}$ construção do relato inicialmente, privilegiou-se a análise individual e longitudinal dos casos e, em um segundo momento, foram ressaltadas as semelhanças entre os mesmos, a partir dos seguintes eixos temáticos: Manifestações maternas de dependência e independência, Sentimentos de ambivalência frente à função materna de cuidar e Experiência curativa das mães.

\section{Caso I (Isadora e Laura) - "Parece assim que tá grudado, sabe?" 4}

Isadora e seu marido (José) tinham um relacionamento de oito anos e estavam casados há dois anos. A mãe iniciou atividade laboral, na qual não permaneceu por

3 Nos três casos escolhidos a autora escutou os áudios de todas as entrevistas realizadas por ela e por outros pesquisadores da equipe e houve contato com as famílias aos 36 e aos 48 meses das crianças.

4 Todos nomes utilizados são fictícios, no intento de preservar a identidade dos participantes. muito tempo em função de dificuldades pessoais que a levaram a procurar ajuda psiquiátrica e iniciar tratamento medicamentoso para depressão. Em seguida, descobriu que estava grávida. Isadora e o marido tiveram duas filhas: Laura e, aproximadamente dois anos mais tarde, Cláudia. A mãe optou por abdicar de sua carreira profissional para cuidar de ambas as meninas, sendo o marido responsável pelo sustento financeiro da família.

Isadora queria engravidar e essa decisão foi tomada em conjunto com José. A gestação foi "tranquila", no entanto a mãe desejava um menino e se mostrou resistente ao descobrir o sexo de Laura, pois "achava menina sem graça" $\left(6 \mathrm{~m}^{5}\right)$. Isadora sempre gostou de gatos e, ainda na gestação, relatou que tinha receio se amaria sua filha tanto quanto amava seus gatos, mas após o nascimento de Laura percebeu que a menina lhe despertava um sentimento intenso: "tenho vários gatos [...] E eu dizia pra mãe 'ah mãe, será que eu vou gostar do nenê, que nem eu gosto do Tobi [gato]?'[...] Daí depois eu disse 'ah, eu amo meu gato, mas ele é só um gato'(risos), passou a ser só um gato. Então é bastante amor, bastante" (6m). Aos seis meses de Laura, a mãe apontou aspectos negativos da função de cuidar, dentre eles, a falta de tempo para as atividades que considerava prazerosas: "não é tudo sempre maravilhoso, às vezes ela acaba me exigindo” (6m).

Aos 12 meses, Isadora demonstrou satisfação em relação à maternidade, mencionando que era algo diferente de todas as outras vivências que teve, apesar de, em alguns momentos, ser bastante cansativo: "já vivi momentos bem legais [...] mas

5 A sigla $6 \mathrm{~m}$ se refere ao momento em que a entrevista foi realizada, no caso, aos seis meses do bebê. O mesmo ocorre com o restante das siglas $(12,18,24,36$ e 48$)$. 
nenhum se compara a ser mãe, nada compensa assim, de ter ela" (12m). Além disso, às vezes, a menina apresentava comportamento difícil, o qual a mãe entendia como um "ataque/chilique", em que a bebê gritava e chorava. Isso apareceu em todas as entrevistas do primeiro ao quarto ano de Laura: "e quando ela tem os chiliques que começa a se pelar e daí, às vezes, eu dou umas palmadas ou espanada de fralda pra ela voltar, ou vou no banheiro, lavo o rosto dai ela meio que se acalma. Pra acabar com o histerismo" (12m). Isadora também mencionou que, em algumas situações, não tinha muita paciência para lidar com o jeito da filha, já que Laura era muito grudada a ela: "às vezes eu quero fazer as minhas coisas e ai ela não desgruda, né?" (12m).

Aos 18 meses de Laura, Isadora demonstrou preocupação em relação ao nascimento de sua segunda filha. A mãe estava grávida de seis meses, mas não mencionou sobre como ocorreu essa gestação. Isadora parecia não estar preparada para se separar de uma filha e receber outra: "esse momento que eu tô vivendo que é a minha preocupação [...] dessa separação que eu vou ter da Laura, que a gente nunca ficou uma noite longe uma da outra. Porque ao mesmo tempo que eu quero curtir a chegada de uma, eu não quero sofrer pela ausência da outra" (18m). Em relação à vivência da função de cuidar, a mãe se descreveu como irritada e sem paciência, atribuindo esses sentimentos, em parte, à gestação da segunda filha. Parecia que a notícia da gravidez havia exacerbado o medo de separação e desorganizado emocionalmente Isadora: " ai eu tô gostando muito, mas eu ando um pouco impaciente" (18m).

Aos 24 meses de Laura nasceu a sua irmã. A mãe parecia estar irritada e encontrava dificuldade em manter a casa organizada, o que a incomodava: "eu ando perdendo muito a paciência, muuuito irritada, coisas que eu não fazia, de gritar, de às vezes até dar uma palmada. [...] uma coisa que me irrita muito é a casa bagunçada. Tá sempre bagunçada. Mesmo" (24m). Isadora demonstrava ter dificuldades em se separar emocionalmente da filha, o que ficava evidente nas transições do desenvolvimento, como o desmame: "não que eu queira manter ela como bebê, mas é uma coisa que, daqui a pouco, ela mesma não vai mais querer, não vai tá mais nem aí, e, então, como eu digo, ela vai ter tão pouco tempo sendo criança e o resto da vida pra ser adulta, né?! Então dá pra aproveitar bem (risos)" (24m).

Aos 36 meses de Laura, Isadora mencionou as mudanças na função materna em relação ao cuidado das duas filhas: "a dificuldade pra mim no momento tá sendo de conciliar as atividades que envolvam as duas" (36m). Também apareceram questões referentes ao sono de Laura, visto que a menina ficava acordada até tarde, acompanhando a mãe: "[o sono] tá ruim, por problema meu assim [...] e ela só vai deitar se eu deitar com ela, parece assim que tá grudado, sabe?" (36m), o que parecia indicar o quanto Isadora também estava grudada à filha. Ao se descrever como mãe, Isadora referiu que estava cansada, pois buscava manter as atividades que fazia anteriormente ao nascimento das filhas, mas nem sempre tinha sucesso: "eu acho que eu falho um pouco nesse sentido de querer fazer tudo certo e dá conta de tudo e não ter esse êxito assim" (36m). A mãe apontou que estava enfrentando dificuldades no convívio com Laura, além de estar vivenciando um período de sobrecarga em casa: "eu cobrava dela coisas que eu não tava conseguindo fazer [...] Projetava nela aquilo que eu não tava conseguindo $n e ́$ " (36m).

A vivência de Isadora enquanto filha e o modelo de sua mãe pareciam reverberar no modo como exercia a função de cuidar de Laura. Ela tentava evitar o modelo de cuidado que recebeu de sua mãe e de seu pai, apesar disso, muitas vezes acabava repetindo algumas atitudes: "minha mãe gritava demais, eu não queria repetir, mas quando eu vejo eu tô gritando, que parece que eu tô usando um microfone" (48m). Por outro lado, Isadora buscava inspiração no exemplo da mãe que também abdicou da carreira profissional para se dedicar ao cuidado das filhas. Em alguns momentos, Isadora parecia perder o controle de determinadas situações e de si mesma: "esse ano meio que foi uma depressão mais intensa assim, engordei muito e isso é uma coisa que me incomoda demais, e não tô conseguindo voltar, então acaba, [...] a frustração, às vezes pra não descontar nelas, eu descontava na comida. Mas tá indo" (48m). Também parecia haver uma dificuldade por parte de Isadora em favorecer a independência emocional de Laura, o que era expresso nos momentos em que ficava longe da menina: "dá uma folga assim, fica um silêncio [...] mas eu sinto falta, muita falta" (48m).

Em síntese, pôde-se observar que o caso de Isadora e Laura foi marcado pela intensidade e urgência da mãe em compartilhar as angústias e dificuldades frente a suas questões pessoais e em relação ao desenvolvimento de Laura. Nesse caso, chama atenção a forma que Isadora se referia ao comportamento da filha, mencionando que Laura tinha "chiliques" e "ataques" e, em função disso, uma grande probabilidade de se tornar uma pessoa histérica e nervosa na vida adulta. Esse comportamento parecia ser a maneira que Laura encontrou para reclamar das coisas que lhe incomodavam, como o fato de mãe e filha estarem "grudadas". Nesse sentido, para Isadora parecia ser difícil oferecer continência às manifestações do comportamento da filha. Em muitos momentos, essa preocupação de Isadora frente ao comportamento de Laura aparentava refletir suas angústias em relação a si mesma, sobretudo em relação à oscilação de peso e à autoestima. Talvez, Isadora projetava sobre Laura as suas questões pessoais, o que demonstrava a sua dificuldade para lidar com o comportamento da menina. Também se destaca a ambivalência da mãe para lidar com as conquistas da filha, especialmente as demonstrações de autonomia. Isadora demonstrava necessitar da dependência da filha para se sustentar enquanto mãe. Contudo, o nascimento da irmã parece que ajudou Laura na sua caminhada em direção à independência e a manter Isadora menos "grudada" à filha. 


\section{Caso 2 (Camila e Bruno) - “Não sei muito bem como conduzir essa história”}

Camila e seu marido (Paulo) eram casados há seis anos. Bruno foi o primeiro filho do casal e aos quatros anos, teve uma irmã, chamada Lara. A mãe se dedicou exclusivamente ao cuidado do filho até o final do seu segundo ano de vida, momento em que Bruno começou a frequentar a creche durante um turno. Na época da gravidez, Camila cursava mestrado e relatou que o bebê era muito desejado, apesar de não ser esperado para aquele momento. A gestação foi um pouco conturbada, pois a mãe estava envolvida com a conclusão dos estudos e, em função disso, Camila costumava conversar com a barriga: "calma, bebê, é só por um tempo. É pra mãe conseguir ficar em casa contigo depois" (6m).

Sobre os primeiros meses após o nascimento de Bruno, Camila relatou que não sabia muito bem como lidar com o filho e falou da dificuldade em identificar as necessidades do bebê: "eu não sabia como pegar, eu não sabia como trocar a fralda. Não sabia nada [...] Dai tu chora junto porque tu não sabe o que tu faz [...] Depois tu vai começando a ficar um pouquinho mais calma (risos)" $(6 \mathrm{~m})$. Camila referiu que ser mãe estava sendo "uma loucura", ao mesmo tempo em que era ótimo. Destaca-se a ambivalência dessa vivência que oscilava entre as experiências positivas e negativas: "resumindo é a coisa mais cansativa do mundo, mas é, é a coisa mais maravilhosa do mundo" (6m).

Aos 12 meses de Bruno, Camila se descreveu como uma mãe "menos paranoica" e parecia estar mais segura para lidar com as demandas do filho: "agora eu tô mais relaxada, tô mais tranquila" $(12 \mathrm{~m})$. Frente à solicitação para descrever um momento que considerava prazeroso na relação com Bruno, Camila demonstrou ter receio da reprovação da entrevistadora: "não briga comigo se disser? (risos) Ai eu adoro dar mamá né [...] Ai é tudo de bom né, porque fica ali, aconchegadinho né" (12m). Apesar disso, a mãe apontou que, no seu entendimento, a amamentação estava sendo: "mais importante pra mim do que pra ele no momento, sabe?" (12m). Justificou essa afirmação tendo em vista que Bruno já comia outros alimentos e que a amamentação estaria a serviço do vínculo mãe-bebê: "o mamá não é mais alimentação [...] É mais de vínculo agora, de carinho, aproximação, aconchego" $(12 \mathrm{~m})$.

Ao se descrever como mãe, Camila sentia que estava falhando em alguns aspectos, o que parecia estar ligado à sua insegurança: "sempre tem alguma coisa que parece que tu tá deixando de fora, que tu não tá conseguindo abraçar, sabe? Sempre tem alguma coisa que tu pensa 'ah, acho que eu tô falhando' [...] mas eu acho que isso é normal, assim. Acho que mãe sempre se culpa um pouco" $(18 \mathrm{~m})$. Dentre as situações que eram difíceis de lidar, Camila mencionou os momentos em que Bruno acordava durante a noite e não conseguia voltar a dormir. A mãe referiu que, por vezes, não sabia o que fazer para o filho retomar o sono. É interessante pensar na estratégia que Camila utilizava para se acalmar e conseguir lidar com Bruno, que pode ser entendida como uma forma de proteger o bebê de suas dificuldades enquanto mãe: "é quando ele acorda e fica chorando que tu não sabe porque que tá chorando, entendeu? [...] e dai as vezes eu vou pro banheiro, dou uma respirada e ele [bebê] fica lá chorando, e ele [marido] fala 'por que tu faz isso?' porque eu preciso respirar... Sabe? Eu preciso sair do contexto e pensar assim.... E dai eu volto" (18m).

Aos 24 meses de Bruno, ao ser questionada sobre como se sentia ao ver o filho crescendo, Camila apontou a ambivalência desse momento: "é legal, mas é dificil". Nesse sentido, a mãe explicou: "é dificil, porque quando eles estão bem bebezinhos, tu pensa assim 'ó! Ele só precisa de mim', depois começa ficar grande, eles começam a querer outras coisas. Daí tu fica, dá um sentimento de um vazio, que vai indo assim. [...] é uma coisa muito contraditória assim. Tem um cantinho do coração que fica apertadinho, mas o outro fica cheio de orgulho" (24m). A mãe também relatou que escolheu abrir mão da sua carreira profissional para cuidar do filho, mas que sentia falta de outras atividades. Esse movimento de Camila era bastante interessante, pois conforme o filho ia conquistando espaços, a mãe percebia que também podia avançar na busca por seus objetivos pessoais: "porque eu sinto como se a minha vida tivesse suspensa, desde que eu ganhei ele, né. Parece que meu mundo se restringiu aqui né, não que isso não seja bom, eu adorei, eu escolhi isso, eu quis isso, ficar só com ele. Mas agora, hã eu já tô querendo expandir meus horizontes de novo" $(24 \mathrm{~m})$. Em relação à disponibilidade para atender às necessidades do filho, Camila mencionou que quando Bruno era menor ela se sentia mais disponível: "eu acho que antes quando ele era bebê, eu tava mais disposta. Agora, eu tenho que me policiar, não é porque ele tá maiorzinho, que ele depende menos de mim" (24m).

Aos 36 meses do filho, Camila relatou que estava se sentindo mais tranquila como mãe. Bruno começou a frequentar a creche no final do segundo ano de vida. Depois disso Camila começou a procurar um emprego, mas encontrou dificuldades: "essa questão de eu tá em casa e eu não tá trabalhando e eu acho que eu tô me autoboicotando de alguma forma porque não é possivel eu não estar conseguindo nada, sabe? [...] O Bruno já está na escola, já faz um ano, já tá adaptado, tá bem, eu acho que eu posso fazer alguma coisa pra mim agora" $(36 \mathrm{~m})$. Camila também mencionou que Bruno estava expressando seu desejo por realizar as atividades de higiene pessoal de forma mais autônoma: "agora que ele quer fazer mais essas coisas sozinho, né [...] ah a roupa ele até quer escolher, às vezes ele não quer que escolha a roupa, normal, mas ele quer fazer mais sozinho" $(36 \mathrm{~m})$.

Poucos meses depois, Camila engravidou e Bruno teve uma irmã (Lara) quando estava com 48 meses. Em relação ao comportamento de Bruno, Camila assinalou que percebia que o filho não solicitava mais tanto a sua presença, especialmente nas brincadeiras. Camila mencionou que essa 
mudança despertava um sentimento de "ninho vazio". Apesar disso, a mãe parecia lidar bem com o crescimento do menino: "o que eu noto mais é essa questão de independência que tá muito evidente, né? Que ele tá se virando mais sozinho, que ele tá literalmente deixando a gente, não preciso tanto de vocês, eu tô indo. Em busca das coisas dele por ele mesmo assim, eu tô achando isso o máximo, né?" (48m).

Os relatos acima revelam que o percurso de Camila e Bruno foi marcado pela perplexidade da mãe diante das conquistas do filho. Essa mãe conseguia, em alguma medida, manter-se discriminada do filho e acompanhava com satisfação os avanços do seu desenvolvimento, respeitando o ritmo e o espaço de Bruno. Nos momentos de dificuldade, Camila parecia precisar reafirmar a sua escolha para seguir adiante, tentando não projetar em Bruno suas angústias e dificuldades em relação à função de cuidar. Conforme Bruno foi crescendo, a mãe sentiu necessidade de retomar sua carreira profissional. Contudo, não teve sucesso em suas tentativas e parece que acabou substituindo esse "fracasso" pela gestação de outro bebê, mantendo a dependência que sustentava o seu lugar de mãe. A todo tempo Camila se referia a sua experiência de forma dicotômica, o que demonstrava certa ambivalência da função de cuidar. Camila também parecia ter dúvidas sobre como "conduzir essa história", o que produzia medos e angústias. Talvez não fosse responsabilidade materna "conduzir" essa história, mas deixar-se conduzir pelo desenvolvimento do filho e pelas próprias vivências da maternidade.

\section{Caso 3 (Aline e Ana) - “Eu queria ser uma mãe melhor do que a mãe que eu tive"}

Aline estava casada com seu marido (Marcos) há 11 anos. O casal desejava muito ter filhos, mas teve dificuldades, sendo que Aline engravidou de Ana após dois anos de tentativas. Pai e mãe exerciam atividade laboral remunerada, e quando Ana nasceu, Aline teve seis meses de licença maternidade. Quando retornou ao trabalho, o cuidado da filha ficou sob responsabilidade de uma pessoa da família, que passou a ser a babá.

Aline relatou que ficou muito feliz quando recebeu a notícia da gravidez, pois queria muito ter uma filha, ressaltando o seu desejo de que fosse uma menina, para a qual inclusive já havia escolhido o nome. Ela mencionou que não tinha um bom relacionamento com sua mãe e temia repetir os cuidados que recebeu: "eu tenho dificuldades com a minha mãe assim, então muito tempo eu fiz terapia e falava sobre isso, que eu não queria repetir algumas coisas que ela tinha feito comigo com os meus filhos assim, né. Então ela repreendia demais, ela agredia fisicamente e tal. E psicologicamente principalmente assim. [...] Que, ao mesmo tempo que eu desejava muito ser mãe eu queria ser uma mãe melhor do que a mãe que eu tive" $(6 \mathrm{~m})$. Quanto à relação com a filha, Aline relatou que nas primeiras semanas foi bastante difícil: "sentia que não ia dar conta. Sentia que era muita responsabilidade pra mim. [...] Porque às vezes ela chorava, não entendia por que ela tava chorando" (6m). Contudo, aos poucos, "estava pegando o jeito" $(6 \mathrm{~m})$.

Aos 12 meses de Ana, Aline mencionou certa ambivalência frente à função de cuidar: "teve fases que eu tava totalmente desesperada e com medo de não dar conta, teve fases que eu achei que tava muito bem da forma como tava funcionando" (12m). A mãe parecia ter ciência de que suas questões pessoais poderiam estar permeando a relação com a filha: "eu acho que é mais uma inquietação assim [...] Ai, não sei, acho que é meu mesmo isso assim né." (12m). Aline mencionava com frequência que não desejava repetir o modelo de cuidados de sua mãe: "esse era o maior receio, por não ter recebido afeto assim, de não conseguir passar isso pra Ana" (12m). Desde os seis meses, a filha ficava sob os cuidados de uma babá e Aline revelou ter conhecimento em relação às atividades da filha, já que a babá descrevia os horários e as atividades que a menina realizava durante o dia: "ela escreve tudo que ela faz com a Ana [...] 'tal hora eu troquei a fralda, tal hora a Ana fez cocô, de tal a tal horário a gente brincou de tal coisa', então ela deixa tudo registrado" $(12 \mathrm{~m})$.

Aos 18 meses de Ana, Aline relatou que não se sentia mais tão insegura: "eu tô me sentindo bem assim porque as inseguranças iniciais já passaram" (18m). A mãe também referiu que o marido saiu do emprego e ficava mais tempo com a filha em casa: "também bate um pouquinho de ciúme agora que o pai dela passa mais tempo com ela [...]então eu gostaria de ter mais tempo com ela, mas enfim, tem que trabalhar né" $(18 \mathrm{~m})$. Aline se descreveu como uma mãe "adequada", visto que conseguia: "ao mesmo tempo demonstrar o carinho por ela, consigo ser afetuosa com ela, consigo dar um certo limite pra ela né [...] eu acho que eu tô conseguindo ir bem assim" (18m). Aline mencionou estar com problemas no trabalho, o que refletia na sua relação com a filha: "é, me causa ansiedade, eu fico muito cansada mesmo assim mentalmente porque é muito excesso de trabalho e cobranças [...] então isso claro interfere nos cuidados com a Ana" (18m).

Aos 24 meses de Ana, Aline parecia estar ciente das suas dificuldades, bem como do quanto as questões de sua infância se atravessavam na vivência da função de cuidar. Ao mesmo tempo, era difícil para a mãe lidar com essas lembranças e sentimentos: "eu acho que eu queria ser de um jeito diferente comigo assim e não com ela [...] Então, na verdade, têm algumas questões mal resolvidas na infância, principalmente na relação com a minha mãe, que de certa forma afetam assim" $(24 \mathrm{~m})$. Ver a filha crescer pareceu ser um momento ambivalente que envolvia satisfação frente às conquistas de Ana, mas também trazia ansiedade em relação ao futuro: "é meio assustador assim né!? Tá, agora ela tá com dois anos, ai tu começa a imaginar como é que vai ser quando ela tiver com cinco, depois quando tiver com dez, com quinze... [...] Então, é legal ver ela crescendo, é legal ver ela tendo opinião própria e personalidade, mas, ao mesmo tempo, gera um pouco de ansiedade" $(24 \mathrm{~m})$. 
Aos 36 meses, percebe-se que a tarefa de cuidar estava atrelada ao crescimento de Ana e isso proporcionava amadurecimento. Aline também ressaltou que houve adaptação da rotina e do modo de lidar com Ana, conforme ambas foram se conhecendo: "eu acho que assim como ela foi crescendo assim, a gente também foi crescendo [...] e a gente foi também adaptando a nossa rotina e nosso jeito de lidar com ela a esse crescimento dela" (36m). Aline se caracterizou como uma mãe que estava "se saindo bem", por ter conseguido fazer diferente do modelo que recebeu: "talvez por tentar ser um pouco diferente do que minha mãe foi. [...] E eu acho que eu tô conseguindo manter esse equilibrio assim né, entre o afeto e limite" (36m). Com 2 anos e 3 meses Ana passou a frequentar a creche e, nesse momento, a mãe notou que a filha estava mais independente: "olha, a maior parte do tempo, tá mais independente assim" (36m). Percebe-se que Aline sempre foi muito crítica em relação a si mesma e aos cuidados da filha: "quando eu vejo alguma coisa, daqui a pouco eu tô impaciente demais com ela em algum momento, eu procuro pensar sobre isso, tentar modificar" (48m). A mãe vivenciou momentos difíceis no último ano, especificamente em relação ao casamento e ao trabalho. Aline se descreveu como uma pessoa estressada, o que contribuía para que ela não conseguisse lidar de modo satisfatório com o que lhe incomodava. Ver as coisas inimagináveis que uma mãe era capaz de fazer com os filhos no trabalho, também parecia assustar Aline: "eu sou muito estressada, dai pra ajudar [...] eu trabalho na maternidade do hospital então eu vejo tudo que é tipo de modelo de mãe possivel né. Inclusive as coisas que tu nunca imagina que uma mãe é capaz de fazer, tu acaba presenciando" (48m). Em relação às questões de independência, Aline apontou que Ana conseguia realizar a maior parte das atividades sozinha, sendo que a mãe considerava isso positivo: "então ela tem autonomia, assim, pra bastante coisa. Eu acho que em geral ela procura fazer mais sozinha, assim. Eu acho que eu me sinto bem, eu valorizo bastante quando ela consegue fazer as coisas" (48m).

De modo geral, identifica-se que o percurso de Aline e sua filha também foi marcado por singularidades. Aline desejava propiciar a Ana, em termos de cuidado, aquilo que não recebeu durante a infância e mesmo na vida adulta. É como se a mãe lutasse contra ela mesma a todo instante, tentando não repetir o modelo de sua própria mãe, o que parecia refletir em um funcionamento rígido de Aline. Nesse caso, também é marcante a presença do pai e o sentimento que isso provocava na mãe, sendo que Aline revelou ter ciúmes da relação entre seu marido e a filha. Ainda, o retorno à atividade laboral parece ter "obrigado" Aline a se desvincular gradativamente de sua filha, visto que a necessidade de trabalhar parecia estar além do desejo da mãe, a qual tentava se manter próxima da filha por meio das anotações da babá.

\section{DISCUSSÃO}

A partir da análise dos três casos e com base na literatura (Caron \& Lopes, 2014; Dias, 2010; Felice, 2007; Winnicott, 1965/2011; Winnicott, 1970/1989), foram identificados três eixos temáticos: Manifestações maternas de dependência e independência, Sentimentos de ambivalência frente à função materna de cuidar e Experiência curativa das mães.

Em relação ao primeiro eixo temático Manifestações maternas de dependência e independência, constatou-se que os bebês vivenciavam o período de dependência relativa e, quando as crianças estavam com quatro anos, conquistavam uma maior independência. Nesse sentido, "entrar e sair" da dependência parecia representar um dilema para as mães, visto que era um movimento exigente (Bick, 1986; Caron \& Lopes, 2014), pois inicialmente era preciso se colocar à disposição do bebê, para que ele pudesse se constituir e, em seguida, se retirar gradativamente para que ele avançasse no seu percurso do desenvolvimento (Henriques et al., 2015; Lopes et al., 2010; Winnnicott, 1965/2011). Tal questão apoia a literatura científica, uma vez que ser capaz de falhar, bem como permitir ao bebê experiências de frustação e descontinuidade são tarefas que produzem sentimentos ambivalentes nas mães (Barbosa et al., 2010; Lopes et al., 2012; Travassos-Rodriguez \& Féres-Carneiro, 2013). Isso está em consonância com a proposição de Winnicott (1951/1993) sobre a mãe suficientemente boa, ou seja, aquela que é capaz de falhar ao longo do processo de desenvolvimento do bebê, conforme o bebê também tem condições emocionais para suportar essa falha.

Desse modo, as manifestações de dependência e independência puderam ser observadas na dificuldade das mães em fazer o movimento, primeiramente, de "entrada" e, em seguida, de "saída" da dependência, o que perpassou a vivência das mães deste estudo (Isadora, Camila e Aline), mesmo que de modo particular e com intensidades diferentes. Frente a isso, entende-se que Isadora pode ter emendado uma gestação na outra, por encontrar dificuldades para lidar com a separação da filha. De modo semelhante, Camila, após se "autoboicotar" na busca por emprego, acabou engravidando novamente. Já Aline parecia ter conseguido fazer o movimento de saída da dependência, sendo que o processo pode ter sido facilitado pelo retorno da mãe ao trabalho.

O desenvolvimento da criança também apareceu como um aliado das mães no processo de separação, visto que durante vários meses a mãe fica à mercê de um bebê que depende dela (Bick, 1986). Conforme o eu se constitui, a criança vai aprendendo a se expressar, demarcando uma mudança na função materna de cuidar (Caron \& Lopes, 2014). Nesse momento, ainda é necessário que a mãe invista no seu filho, mas não é mais preciso que ela se empreste a ele, diminuindo 
a demanda de cuidados. Essa dependência inicial também coloca a mãe em uma situação de desamparo, muitas vezes semelhante ao próprio desamparo vivenciado pelo bebê (Bick, 1986; Lopes et al., 2010; Winnicott, 1987/2006), fazendo com que a mãe reviva a dependência junto ao seu filho. É como se a mãe estivesse no que pode ser chamado de um "não lugar", em que ela se empresta ao bebê, mas não pertence a ele e nem à sua identidade anterior. Tais questões apontam o quanto é custoso para a mãe estar disponível para outro ser que depende dela e, gradativamente, deixar esse lugar de indiscrimação (Henriques et al., 2015). Frente a isso, observa-se que o modo como a mãe vivencia a função materna também está relacionado ao desenvolvimento infantil do próprio filho, que a auxilia nesse processo (Caron \& Lopes, 2014).

Quanto ao eixo temático Sentimentos de ambivalência frente à função materna de cuidar, destaca-se a verbalização das mães em relação aos aspectos positivos da maternidade, bem como às dificuldades encontradas no exercício dessa função. Isso inclui o reconhecimento de uma dimensão real da função materna, que abrange aspectos como a satisfação e os desafios diários decorrentes do cuidado de um bebê, que se encontra frágil e dependente (Bick, 1986). Strapasson e Nedel (2010) destacaram a presença de dificuldades e sentimentos ambivalentes no pós-parto imediato. Nesse sentido, é possível observar que tais vivências maternas parecem se estender ao longo do desenvolvimento, uma vez que sentimentos semelhantes, dentre eles tristeza, cansaço e irritação, também foram encontrados em outros estudos que pesquisaram diferentes momentos da primeira infância (Azevedo \& Arrais, 2005; Henriques et al., 2015; Murray, 2015; Zanatta \& Pereira, 2015). Esses aspectos foram mencionados por todas as mães do presente estudo, em que se destaca a fala de Camila, que a todo instante referia que ser mãe era "uma loucura, mas era ótimo".

Winnicott (1958/2000) também apontou que sentimentos de ódio estão presentes na maternidade, haja vista que no processo de adaptação é necessário que a mãe tolere a interposição do filho na sua vida pessoal. De modo semelhante, Stern (1997) mencionou a reorganização da identidade como uma das tarefas da mãe após o nascimento do filho, em que é fundamental que a mulher consiga se adaptar às mudanças dessa nova função. Nesse momento, a mãe também altera os seus investimentos emocionais, sua distribuição de tempo e energia, bem como suas atividades, podendo estar mais voltada ao bebê do que às suas questões pessoais/profissionais, por exemplo (Laney et al., 2015).

Diante disso, surge um novo desafio que consiste em a mãe conter as suas angústias e as do bebê, ao mesmo tempo em que mantém a continuidade de ser e une sua identidade anterior às novas experiências enquanto mãe (Travassos-Rodriguez \& Féres-Carneiro, 2013; Winnicott, 1958/2000). Freud (1910/1980) também postulou sobre a presença de ambivalência na relação mãe e filho, uma vez que ao considerar o amor, é necessário levar em conta o ódio e todo dualismo pulsional.
Os sentimentos de ambivalência também pareciam estar relacionados ao desenvolvimento dos filhos e acompanharam as três mães do presente estudo. É como se cada conquista fosse comemorada por indicar um avanço, ao mesmo tempo em que havia a consagração da perda do "bebê de colo". Nesse sentido, a admiração e o encantamento das mães pelas conquistas do filho pareciam vir acompanhados por um vazio, o que é referido pela literatura como próprio dessa fase (Lopes et al. 2009; Lopes et al., 2012). Apesar desses sentimentos ambivalentes, prevaleceu a satisfação em relação ao desenvolvimento infantil, o que também foi apontado por Luthar e Cicciola (2016). Esses aspectos puderem ser observados nas declarações constantes de Isadora, Camila e Aline sobre as conquistas dos filhos, as quais traziam alegria, ao mesmo tempo davam a sensação de vazio.

Em decorrência desses sentimentos de ambivalência, foi possível observar que a função materna de cuidar parecia exigir que essas mães estivessem disponíveis e se entregassem aos seus filhos, o que era bastante trabalhoso e custoso em termos emocionais. Essa disponibilidade era necessária para investir no filho para que ele pudesse "nascer" psicologicamente e seguir crescendo. Determinado descontrole ou cansaço pareceu permear as três mães em algum momento de suas trajetórias, mas como afirmou Camila, era necessário reafirmar a escolha para seguir adiante - "eu quis isso, é minha escolha".

O eixo temático Experiência curativa das mães se relaciona ao entendimento de que a epistemologia da palavra cuidado se refere à cura (Winnnicott, 1970/1989). Nesse sentido, Winnicott (1970/1989) propõe que a imaturidade, a doença e a velhice são estados que legitimam a dependência, a qual requer confiabilidade. $\mathrm{O}$ autor faz referência à dependência natural do indivíduo que suscita nos cuidadores uma tendência a proporcionar condições que favoreçam o crescimento individual.

Esses aspectos estão relacionados à prática clínica, mas podem ser estendidos para a dupla mãe-bebê, uma vez que a dependência e a confiabilidade foram pensadas a partir dessa relação e fazem parte do cuidado (Dias, 2010). Nesse sentido, entende-se que a vivência da função materna de cuidar remete à uma situação de imaturidade do bebê, no qual ele depende da mãe para que possa se constituir. Para que isso ocorra, é necessário que a mãe também entre nessa dependência e seja capaz de manter uma comunicação empática com o bebê. Essa relação estabelecida entre a dupla pode estar associada à experiência curativa, em que as mães, ao cuidarem dos seus bebês, também cuidam de si mesmas. É como se a mãe tivesse uma oportunidade de fazer diferente do modelo parental e reeditar os cuidados recebidos durante sua infância. De modo semelhante, um estudo de Felice (2007) apontou que a maternidade pode ser entendida como uma experiência transformadora, em que a mãe, por meio do cuidado do filho, consegue modificar parcialmente as vivências negativas com a própria mãe em aspectos positivos na relação com o bebê. 
Tais aspectos podem ser observados no caso de Aline que trazia marcas de sua infância e tentava, a todo custo, reeditar sua história, fazendo diferente em relação aos cuidados de Ana. Isadora também relatava que, apesar de não desejar, quando ficava irritada, acabava reproduzindo o modelo materno. Por outro lado, Camila parecia repetir os cuidados de sua mãe na relação com o filho. Nesse sentido, a literatura também aponta que há uma tendência da mulher em se identificar com o modelo de relação estabelecido com a figura materna na infância (Bick, 1986; Felice, 2007; Lopes et al., 2010). Assim, a vivência de cuidados percebidos como satisfatórios, bem como situações vivenciadas de forma não positiva, pode repercutir no exercício da função materna de cuidar (Zanatta \& Pereira, 2015).

A partir do exposto, identifica-se que cada dupla mãe-bebê do presente estudo teve um percurso singular, caracterizado por conquistas e percalços, mas que à sua maneira se organizou para seguir adiante. Além disso, é possível verificar que o estado de "loucura normal", proposto por Winnicott (1958/2000), é vivenciado pelas mães nos meses iniciais do desenvolvimento do bebê com intensidades e em situações diferentes. E, conforme avançam as conquistas da criança, é exigido das mães uma mudança na função materna de cuidar. Junto a isso, surgem novos desafios e adaptações, as quais são necessárias, mas nem sempre são vivenciadas com tranquilidade. Desse modo, essas vivências parecem ser compartilhadas pela maioria das mães e, apesar da ambivalência, são naturais e vão se organizando ao longo do desenvolvimento e do percurso de cada dupla mãe-criança.

As reflexões acerca da vivência materna da função de cuidar trazem contribuições importantes para a clínica, visto que, no momento que se conhece minimamente o que essas mães vivenciam, é possível se ter uma escuta mais sensível. Oferecer acolhimento em situações que talvez elas se sintam desemparadas e dar suporte para que deem conta das fragilidades pode permitir que essas mães consigam lidar melhor com esse período carregado de transformações. Ainda, conhecer as vivências maternas permite desmistificar a ideia de uma maternidade ideal, permeada somente por aspectos positivos. Apesar das conquistas e da satisfação encontrada nessa trajetória, as mães também se deparam com momentos difíceis, que são naturais, mas muitas vezes não são vivenciados dessa forma.

Ademais, considera-se relevante refletir de que modo se pode ajudar ou, até mesmo, aliviar essas mães que apresentam angústia, ambivalência e dúvidas em relação à função materna de cuidar. Nesse sentido, entende-se que se colocar à disposição das mães por meio da escuta pode contribuir para minimizar esses sentimentos. Nota-se que se apresentar sensível ao peso de "conduzir" a história dos filhos também deve ser considerado, uma vez que as mães são responsáveis por facilitar o desenvolvimento dos seus bebês e, não necessariamente, em conduzi-lo. De tal modo, é importante que as mães sejam encorajadas em seu saber, ao mesmo tempo em que sejam acolhidas em suas angústias.

Como limitação, salienta-se o caráter mais fechado dos instrumentos, bem como o contato das mães com diferentes entrevistadoras ao longo do projeto, visto que esse aspecto pode ter perpassado a forma como as questões foram abordadas e/ou exploradas. Além disso, algumas questões não foram contempladas no presente estudo e ficam como sugestão para pesquisas futuras. Dentre elas, destaca-se a importância de que essa temática seja investigada desde a gestação, bem como em famílias com configurações distintas. Ademais, considera-se relevante que o estudo dessa temática seja estendido para outros contextos, como o da prematuridade e de doença crônica. Entende-se, também, que a participação do pai no cuidado do filho e a relação da figura paterna com a função materna de cuidar merecem ser investigadas.

Diante de poucos estudos longitudinais que abordam os aspectos subjetivos do cuidar, salienta-se a importância de considerar os sentimentos ambivalentes, as dificuldades e as satisfações, como aspectos naturais que fazem parte da vivência materna. Além disso, a função materna de cuidar parece se tratar de uma construção realizada no contexto da relação mãe-bebê, em que a mãe gesta o filho no ventre e em termos psíquicos, e, de modo semelhante, a criança também auxilia a mãe a se gestar em sua função de cuidar.

\section{REFERÊNCIAS}

Al-Maadadi, F., \& Ikhlef, A. (2015). What mothers know about child development and parenting in Qatar: Parenting cognitions and practices. The Family Journal: Counseling and Therapy for Couples and Families, 23(1) 65-73. doi: $10.1177 / 1066480714555669$

Azevedo, K. R., \& Arrais, A. R. (2005). O mito da mãe exclusiva e seu impacto na depressão pós-parto. Psicologia: Reflexão e Crítica, 19(2), 269-276. doi: 10.1590/S010279722006000200013.

Barbosa, F. A., Machado, L. F. V., Vilela e Souza, L., \& ScorsoliniComin, F. (2010). Significados do cuidado materno em mães de crianças pequenas. Barbarói, 33, 28-49. Retirado de http://pepsic.bvsalud.org/scielo.php?script=sci_arttext\&pid $=$ S0104-65782010000200003

Bick, E. (1986). Further considerations of the function of the skin in early object relations - findings from infant observation into child and adult analysis. British Journal of Psychotherapy, 2, 292-299.

Caron, N. A., \& Lopes, R. C. S. (2014). Aprendendo com as mães e os bebês sobre a natureza humana e a técnica analítica. Porto Alegre: Dublinense.

Dias, E. O. (2003). A teoria do amadurecimento de D. W. Winnicott. Rio de Janeiro: Imago. 
Dias, E. O. (2010). O cuidado como cura e como ética. Winnicott e-prints, 5(2), 21-39. Retirado de http://pepsic.bvsalud.org/ scielo.php?script=sci_arttext\&pid=S1679-432X2010000 $200002 \& \operatorname{lng}=$ pt\&tlng $=$ pt.

Epstein, R. (2011). El relato y la realidad. In M. Vorchheimer (Coord.), XXXIII Simposio Anual: Relatos de la clínica. Buenos Aires: Asociación Psicoanalítica de Buenos Aires.

Felice, E. M. (2007). Transformação e "cura" através da experiência de ser mãe. Psychê, 11(21), 145-159. Retirado de: http:// pepsic.bvsalud.org/scielo.php?script $=$ sci_arttext\&pid $=\mathrm{S} 1415$ 11382007000200010

Freud, S. (1980). Leonardo da Vinci e uma lembrança de sua infância. In J. Strachey (Ed. e Trad.), Edição Standard brasileira das obras psicológicas completas de Sigmund Freud (Vol. 1). Rio de Janeiro: Imago. (Trabalho original publicado em 1910)

Haavind, H. (2011). Loving and caring for small children: Contested issues for everyday practices. Nordic Psychology, 63(2), 24-48. doi: 10.1027/1901-2276/a000031

Henriques, M. S. M. T., Falbo, A. R., Sampaio, M. A., Fonte, M. L. A., \& Krause, D. F. (2015). O exercício da função materna em mães de filhos obesos na perspectiva da psicanálise. Revista Latinoamericana de Psicopatologia Fundamental, 18(3), 461475. doi: 10.1590/1415-4714.2015v18n3p461.4

Krippl, M., Ast-Scheitenberger, S., Bovenschen, I., \& Spangler, G. (2010). Maternal perception of infants' expressions of emotion. Journal of Psychophysiology, 24(3), 173-185. doi:10.1027/0269-8803/a000008

Laney, E. K., Hall, M. E. L., Anderson, T. L., \& Willingham, M. M. (2015). Becoming a mother: The influence of motherhood on women's identity development. Identity: An International Journal of Theory and Research, 15(2), 126-145. doi: 10.1080/15283488.2015.1023440

Lopes, R. C., Prochnow, L., \& Piccinini, C. A. (2010). A relação da mãe com suas figuras de apoio femininas e os sentimentos em relação à maternidade. Psicologia em Estudo, 15 (2), 295-304. doi: $10.1590 / \mathrm{S} 1413-73722010000200008$

Lopes, R. C. S., Vivian, A. G., Oliveira, D. S., Silva, C. V., Piccinini, C. A., \& Tudge, J. R. H. (2009). "Quando eles crescem, eles voam": Percepções e sentimentos maternos frente ao desenvolvimento da criança dos 18 aos 20 meses. Psicologia em Estudo, 14(2), 221-232. doi:10.1590/ s1413-73722009000200002

Lopes, R. C. S., Vivian, A. G., Oliveira, D. S., Deluchi, M., Tudge, J., \& Piccinini, C. A. (2012). Sentimentos maternos frente ao desenvolvimento da criança entre 24 e 28 meses. Estudos de Psicologia, 29(1), 737-749. doi: 10.1590/ S0103-166X2012000500010.

Luthar, S. S., \& Ciciolla, L. (2016). What it feels like to be a mother: Variations by children's developmental stages. Developmental Psychology, 52(1), 143-154. doi: 10.1037/dev0000062

Mordcovich, N. (2011, novembro). Una contribución a la idea de "relato". In M. Vorchheimer (Coord.), XXXIII Simposio Anual: Relatos de la clínica. Simpósio realizado pela Asociación Psicoanalítica de Buenos Aires, Buenos Aires, Argentina.

Murray, M. (2015). Back to work? Childcare negotiations and intensive mothering in Santiago de Chile. Journal of Family Issues, 36(9), 1171-1191. doi: 10.1177/0192513X14533543
Núcleo de Infância e Família/NUDIF/CRESCI. (2011a). Entrevista sobre a Maternidade $-6^{\circ}$ mês. Instrumento não publicado. Instituto de Psicologia, Universidade Federal do Rio Grande do Sul, Porto Alegre, RS.

Núcleo de Infância e Família/NUDIF/CRESCI. (2011b). Entrevista sobre o Desenvolvimento da Criança $-6^{\circ}$ mês. Instrumento não publicado. Instituto de Psicologia, Universidade Federal do Rio Grande do Sul, Porto Alegre, RS.

Núcleo de Infância e Família/NUDIF/CRESCI. (2012). Entrevista sobre a relação mãe-bebê aos 24 meses. Instrumento não publicado. Instituto de Psicologia, Universidade Federal do Rio Grande do Sul, Porto Alegre, RS.

Piccinini, C. A., Becker, S. M. S., Martins, G. D. F., Lopes, R. C. S., \& Sperb, T. (2011). Impacto da creche no desenvolvimento socioemocional e cognitivo infantil: Estudo longitudinal do sexto mês de vida do bebê ao final dos anos pré-escolares - CRESCI. Projeto de pesquisa não publicado. Instituto de Psicologia, Universidade Federal do Rio Grande do Sul, Porto Alegre, RS.

Strapasson, M. R., \& Nedel, M. N. B. (2010). Puerpério imediato: Desvendando o significado da maternidade. Revista Gaúcha de Enfermagem., 31(3), 521-8. Retirado de http://seer. ufrgs.br/index.php/RevistaGauchadeEnfermagem/article/ view/12897/10883

Stake, R. E. (2006). Multiple case study analysis. New York: The Guilford Press.

Stern, D. N. (1997). A constelação da maternidade: O panorama da psicoterápica pais-bebê. Porto Alegre: Artes Médicas.

Travassos-Rodriguez, F., \& Féres-Carneiro, T. (2013). Maternidade tardia e ambivalência: Algumas reflexões. Tempo Psicanalitico, 45(1), 111-121. Retirado de http:// pepsic.bvsalud.org/scielo.php?script=sci_arttext\&pid=S0101$48382013000100008 \& \operatorname{lng}=$ pt\&tlng $=$ pt.

van der Pol, L. D., Groeneveld, M. G., van Berkel, S. R., Endendijk, J. J., Hallers-Haalboom, E.T, Bakermans- Kranenburg, M. J., Mesman, J. (2015). Fathers' and mothers' emotion talk with their girls and boys from toddlerhood to preschool age. Emotion, 15 (6), 854-864. doi: 10.1037/emo0000085

Winnicott, D. W. (1983). O ambiente e os processos de maturação. Porto Alegre: Artes Médicas. (Trabalho original publicado em 1965)

Winnicott, D. W. (1989). Tudo começa em casa. São Paulo: Martins Fontes. (Trabalho original publicado em 1970)

Winnicott, D. W. (1993). Textos selecionados: Da pediatria à psicanálise. Rio de Janeiro: Francisco Alves (Trabalho original publicado em 1951)

Winnicott, D. W. (2000). Da pediatria à psicanálise: Obras escolhidas. Rio de Janeiro: Imago. (Trabalho original publicado em 1958)

Winnicott, D. W. (2006). Os bebês e suas mães. São Paulo: Martins Fontes. (Trabalho original publicado em 1987)

Winnicott, D. W. (2011). A família e o desenvolvimento individual. São Paulo: Martins Fontes. (Trabalho original publicado em 1965)

Zanatta, E., \& Pereira, C. R. R. (2015). "Ela enxerga em ti o mundo": A experiência da maternidade pela primeira vez. Temas em Psicologia, 23(4), 959-972. doi: 10.9788/ TP2015.4-12 